\title{
Determinan Niat Aparatur Daerah untuk Melakukan Whistleblowing pada Konteks Fraud
}

\author{
Mardah' \\ Fakultas Ekonomi dan Bisnis \\ Universitas Muhammadiyah \\ Palopo, Indonesia
}

\author{
Zikra Supri ${ }^{2}$ \\ Fakultas Ekonomi dan Bisnis \\ Universitas Muhammadiyah \\ Palopo, Indonesia
}

\author{
Nispa Sari ${ }^{3}$ \\ Fakultas Ekonomi dan Bisnis \\ Universitas Muhammadiyah Palopo, Indonesia
}

\begin{abstract}
Surel:dmardah@gmail.com
ABSTRAK

Penelitian bertujuan menganalisis komitmen organisasi, tingkat keseriusan kecurangan, dan personal cost terhadap niat whistleblowing fraud aparatur daerah Kota Palopo. Pengambilan sampel menggunakan teknik purposive sampling. Sebanyak 120 responden digunakan sebagai sampel penelitian. Sampel merupakan a paratur daerah yang bekerja pada Dinas PUPRdan BPKAD. Teknik analisis data dilakukan dengan metode analisis regresi linear berganda dengan aplikasi SPSS V.22. Hasil penelitian menunjukkan bahwa tingkat keseriusan kecurangan berpengaruh terhadap niat whistleblowing terhadap fraud aparatur daerah Kota Palopo. Sementara itu, komitmen organisasi dan personal cost tidak berpengaruh terhadap niat whistleblowing fraud aparatur daerah Kota Palopo.
\end{abstract}

Kata Kunci: Komitmen Organisasi; Tingkat Keseriusan Kecurangan; Personal Cost; Niat Whistleblowing Fraud.

\section{Determinants of Local Apparatus' Intention to Whistleblowing in Fraud Context}

\section{ABSTRACT}

This study aims to analyze organizational commitment, level of seriousness of fraud, and personal costs on the intention of whistleblowing fraud by the local apparatus of Palopo City. Sampling using purposive sampling technique. A total of 120 respondents were used as research samples. The sample is local officials who work at the PUPR and BPKAD offices. The data analysis technique was carried out using multiple linear regression analysis method with SPSS V.22 application. The results of the study indicate that the seriousness of fraud affects the whistleblowing intention of the regional apparatus of Palopo City. Meanwhile, organizational commitment and personal costs have no effect on the intention of whistleblowing fraud by the Palopo City apparatus.

Keywords: Organizational Commitment; Fraud Seriousness Level; Personal Costs; Intention of Whistleblowing Fraud.

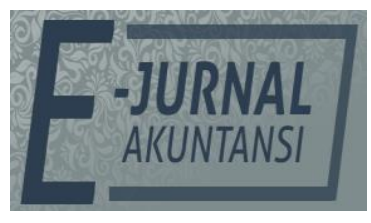

e-ISSN 2302-8556

Vol. 31 No. 11

Denpasar, November 2021 Hal. 2842-2852

DOI

10.24843/EJA.2021.v31.i11.p13

PENGUTIPAN:

Mardah, M., Supri, Z., \& Sari, N. (2021). Determinan Niat Aparatur Daerah untuk Melakukan Whistleblowing pada Konteks Fraud. E-Jurnal Akuntansi, 31(11), 2842-2852

RIWAYAT ARTIKEL: Artikel Masuk: 19 Agustus 2021 Artikel Diterima: 25 November 2021

Artikel dapat diakses: https:/ / ojs.unud.ac.id/index.php/Akuntansi/ index 


\section{PENDAHULUAN}

Kecurangan termasuk pelanggaran hukum karena bersifat menipu dan bisa merugikan pihak lain. Kecurangan (fraud) adalah tindakan yang sengaja dilakukan demi memperoleh keuntungan untuk diri sendiri maupun kelompok. Selain hanya memberikan keuntungan pada beberapa pihak, fraud juga memiliki dampak yang fatal bagi lingkungannya seperti buruknya citra perusahaan/organisasi tempatnya bekerja, bisa merusak moril dari karyawan lainnya, serta masih banyak lagi dampak negatif yang lain. Korupsi (corruption) adalah satu dari beberapa jenis fraud yang paling banyak terjadi di Indonesia. Hal ini sejalan dengan hasil dari Survei Fraud Indonesia 2019 oleh ACFE (Association of Certified Fraud Examiners) Indonesia Chapter yakni sebanyak 64,4\% dari 239 responden menunjukkan bahwa fraud yang paling banyak terjadi di Indonesia adalah korupsi. Selanjutnya sebanyak $69,9 \%$ responden juga menyebutkan bahwa korupsi merupakan tindakan fraud yang teramat merugikan di Indonesia (Association of Certified Fraud Examiners Indonesia Chapter, 2019).

Berdasarkan Laporan Tren Penindakan Korupsi yang diterbitkan oleh ICW pada Semester I tahun 2020, menunjukkan bahwa sektor pemerintahan menempati urutan kedua dengan kerugian negara mencapai Rp18,2 miliar. Pada lembaga pemerintah kota telah terjadi sebanyak 11 kasus (Indonesian Corruption Watch, 2020). Salah satu kasus korupsi yang terjadi dalam lingkup pemerintah kota yakni kasus dugaan korupsi proyek perencanaan Sistem Penyediaan Air Minum (SPAM) di Kota Palopo, Sulawesi Selatan (Sulsel). Kasus ini dibenarkan oleh Direktur Reskrimsus Polda Sulsel, Kombes Polisi Yudhiawan Wibisono saat dikonfimasi pada Selasa, 5 November 2019. Dari ketujuh pejabat yang ditetapkan sebagai tersangka, dua diantaranya adalah pejabat Pemkot Palopo yakni dua orang selaku Pejabat Pembuat Komitmen, dua orang selaku Pokja, dan tiga lainnya selaku Direktur dari masing-masing PT yang terlibat dalam proyek tersebut. Proyek ini di tahun anggaran 2016 senilai Rp15.049.110.000, karena pengerjaannya tidak sesuai spesifikasi maka mengakibatkan kerugian keuangan negara berdasarkan hasil perhitungan BPK RI sebesar Rp5.543.391.996 (Padmasari, 2019).

Ada beberapa cara yang bisa dilakukan untuk meminimalkan kesempatan dalam melakukan kecurangan. Salah satu caranya adalah dengan menciptakan sistem pelaporan pelanggaran/kecurangan (whistleblowing system) (Albrecht etal., 2014). Selain itu, Mediaty et al. (2020) mengungkapkan bahwa melakukan whistleblowing merupakan salah satu cara yang bisa dilakukan untuk mengurangi kecurangan yang terjadi di pemerintahan. Definisi whistleblowing seperti yang diungkapkan oleh Brennan dan Kelly (2007) adalah pengungkapan yang dilaksanakan baik oleh karyawan maupun mantan karyawan sebuah organisasi terhadap suatu operasi yang melanggar hukum (ilegal), tidak bermoral, dan tidak memiliki legalitas hukum atas kendali dari pimpinannya kepada seseorang ataupun organisasi yang bisa saja akan menimbulkan suatu efek berupa tindakan perbaikan.

Berdasarkan dari teori perilaku terencana telah memberikan penjelasan bahwa perilaku yang dilakukan oleh seseorang muncul karena ada niat untuk melakukan suatu perilaku. Theory of Planned Behavior yang dikemukakan oleh Ajzen (1991) yaitu untuk memperkirakan serta memahami dampak apa saja yang 
ditimbulkan dari niat untuk berperilaku, mengidentifikasikan strategi yang bertujuan untuk mengubah perilaku dan juga memberi penjelasan dari perilaku manusia yang nyata. Niat memiliki peran penting untuk menentukan tindakan whistleblowing, dimana niat yang semakin kuat yang dimiliki oleh seseorang demi melaksanakan suatu tindakan maka akan menimbulkan kemungkinan yang semakin besar pula terhadap niat tersebut dapat dilakukan yang berbentuk sebuah tindakan. Organisasi penting mengetahui faktor-faktor apa saja yang dapat berpengaruh terhadap niat dari pegawai dalam melaksanakan suatu tindakan whistleblowing sehingga bisa merencanakan sejak dini suatu kebijakan maupun sistem whistleblowing yang lebih efektif.

Penelitian sebelumnya yang berkaitan dengan minat dan niat dalam melakukan whistleblowing telah mengungkap beberapa faktor yang mempengaruhi, diantaranya komitmen organisasi, tingkat keseriusan kecurangan, dan personal cost. Busra et al. (2019) mengemukakan apabila seorang pegawai telah mempunyai sebuah komitmen yang kuat terhadap organisasinya, maka pegawai bakal menjalankan sebuah tindakan yang prososial serta akan melakukan pelaporan terhadap semua bentuk dari tindakan kecurangan yang bisa merugikan organisasinya.

Dalam teori perilaku terencana, komitmen organisasi didasarkan pada subjective norms (norma subjektif). Pegawai yang melihat bahwa terdapat tindakan kecurangan yang bisa mengganggu keberhasilan dari tujuan organisasi, maka pegawai tersebut akan senantiasa untuk mengungkapkannya. Penelitian yang telah dilakukan oleh Marliza (2018) dan Aida et al. (2019) menunjukkan bahwa benar ada pengaruh yang positif komitmen organisasi terhadap niat untuk melakukan tindakan whistleblowing. Sartika dan Mulyani (2020) menemukan hasil penelitian yang berbeda yakni komitmen organisasi tidak berpengaruh pada niat melakukan whistleblowing. Menurut Sartika dan Mulyani itu karena dalam sebuah organisasi dimana pegawainya mempunyai komitmen organisasi yang rendah akan berdampak pada kurangnya keyakinan dan loyalitas.

$\mathrm{H}_{1}$ : Komitmen organisasi berpengaruh terhadap niat whistleblowing fraud aparatur daerah Kota Palopo.

Tingkat keseriusan kecurangan merupakan ukuran dari besarnya keseriusan pelanggaran yang bisa merugikan organisasi. Organisasi bakal mengalami efek kerugian yang jauh lebih besar dari wrongdoing yang lebih serius daripada wrongdoing yang kurang serius (Winardi, 2013). Tingkat keseriusan kecurangan berhubungan dengan attitude toward behavior atau sikap terhadap perilaku dalam teori perilaku terencana. Dampak lebih besar yang diterima oleh perusahaan atau organisasi sebagai akibat dari kecurangan, maka akan menumbuhkan niat yang lebih besar juga dari diri pegawai untuk melakukan tindakan pelaporan kecurangan tersebut. Penelitian oleh Aidaet al. (2019) menemukan hasil dimana tingkat keseriusan kecurangan memiliki pengaruh positif terhadap minat PNS dalam melakukan tindakan whistleblowing. Hasil yang sejalan juga ditemukan oleh Alwi \& Helmayunita (2020) dimana variabel tingkat keseriusan kecurangan terbukti berpengaruh terhadap intention whistleblowing. Namun penelitian oleh Sartika \&c Mulyani (2020) menemukan hasil yang berbeda dimana tingkat keseriusan kecurangan tidak berpengar uh pada niat melakukan whistleblowing. 
$\mathrm{H}_{2}$ : Tingkat keseriusan kecurangan berpengaruh terhadap niat whistleblowing fraud aparatur daerah Kota Palopo.

Personal cost merupakan suatu dampak yang bisa berupa balas dendamyang akan diterima oleh individu jika melaporkan suatu tindakan kecurangan yang diketahuinya. Menurut Septianti (2013) personal cost menjadi suatu alasan utama yang menjadi penyebab seseorang tidak berkeinginan untuk melaporkan dugaan pelanggaran. Pada teori perilaku terencana, personal cost ini didasarkan pada Perceived behavioral control (persepsi kontrol perilaku). Seseorang akan memikirkan kemungkinan terburuk atau risiko yang nantinya akan diterima saat melaporkan suatu tindak kecurangan. A pabila kemungkinan dampak yang akan diterimanya kecil, maka akan cenderung melakukan whistleblowing. Penelitian oleh Setyawatiet al. (2015) menemukan jika personal cost tidak berpengaruh signifikan terhadap niat melakukan whistleblowing. Hal yang sama juga dikemukakan dalam penelitian Busra et al. (2019) dan Aida et al. (2019) dimana tidak ada pengaruh personal cost terhadap niat melakukan whistleblowing. Penelitian dari Alwi dan Helmayunita (2020) menemukan hasil yang berbeda yakni variabel personal cost of reporting berpengaruh positif pada intention whisteblowing.

$\mathrm{H}_{3}$ : Personal cost berpengaruh terhadap niat whistleblowing fraud aparatur daerah Kota Palopo.

\section{METODE PENELITIAN}

Penelitian dilakukan di Kantor Pemerintahan yang berada di Kota Palopo selama tiga (3) bulan, yaitu dimulai pada bulan April sampai Juni 2021. Populasi penelitian terdiri dari aparatur daerah Kota Palopo dengan pengambilan sampel menggunakan teknik Purposive Sampling. Adapun kriteria sampel yang akan digunakan pada penelitian ini yaitu aparatur yang bekerja di organisasi perangkat daerah Kota Palopo yang rawan terjadi kasus kecurangan dan aparatur yang sudah bekerja minimal 3 tahun. Semakin lama masa kerja dari aparatur, maka akan semakin memperkuat niat untuk mengambil tindakan whistleblowing dikarenakan telah memahami seluk beluk dan kondisi lingkungan tempat bekerja. Data primer dan data sekunder merupakan sumber data yang akan digunakan. Data primer berupa data kuesioner yang berasal dari responden, sedangkan data sekunder berupa dokumentasi, artikel, jurnal, dan berita.

Teknik pengumpulan data menggunakan kuesioner atau angket dengan menggunakan daftar pernyataan yang bersifat tertutup karena telah disediakan alternatif-alternatif jawaban. Dalam kuesioner telah tersedia petunjuk pengisian agar memudahkan responden dalam mengisi jawaban. Akibat dari masa pandemi saat ini, penyebaran kuesioner dalam bentuk hard copy dilakukan dengan cara dititipkan pada bagian kepegawaian dan akan diambil kembali pada saat pengisian kuesioner oleh responden telah rampung. Kuesioner yang dibagikan kepada responden terdiri dari masing-masing 7 pernyataan untuk tiap variabel yakni variabel komitmen organisasi, tingkat keseriusan kecurangan, personal cost, dan variabel niat whistleblowing fraud. Sehingga total pernyataan yang ada sebanyak 28 pernyataan. Pengukuran kuesioner menggunakan skala likert empat poin, yaitu: nilai 1 = Sangat Tidak Setuju (STS), 2 = Tidak Setuju (TS), 3 = Setuju (S), dan 4 = Sangat Setuju (SS). 
Data yang telah diperoleh nantinya akan diuji menggunakan analisis deskriptif, uji validitas, uji reliabilitas, dan analisis regresi linear berganda dengan bantuan komputer melalui aplikasi SPSS versi 22. Adapun rumus regresi linear berganda pada penelitian ini adalah sebagai berikut.

$Y=\alpha+\beta_{1} X_{1}+\beta_{2} X_{2}+\beta_{3} X_{3}+\varepsilon$

Keterangan:

Y $\quad=$ Niat Whistleblowing Fraud

a $\quad=$ Konstanta

$\beta \quad=$ Koefesien regresi

$\mathrm{X}_{1} \quad=$ Komitmen Organisasi

$\mathrm{X}_{2} \quad=$ Tingkat Keseriusan Kecurangan

$\mathrm{X}_{3} \quad=$ Personal Cost

$\varepsilon \quad=$ Error

\section{HASIL DAN PEMBAHASAN}

Penelitian bersumber pada data primer berupa kuesioner yang dibagikan kepada sampel yang memenuhi kriteria purposive samplingyakni Dinas Pekerjaan Umum dan Penataan Ruang (PUPR) serta Badan Pengelolaan Keuangan dan Aset Daerah (BPKAD) Kota Palopo. Jumlah sampel yang diperoleh adalah 121 sampel. Akan tetapi dari keseluruhan sampel tersebut hanya 120 sampel yang memenuhi kriteria dan dapat diuji.

Tabel 1. Hasil Analisis Statistik Deskriptif

\begin{tabular}{|c|c|c|c|c|c|c|c|}
\hline \multirow[b]{2}{*}{ Variabel } & \multirow{2}{*}{$\begin{array}{c}\text { Item } \\
\text { Pernyataan }\end{array}$} & \multicolumn{4}{|c|}{ Frekuensi dan Persentase } & \multirow{2}{*}{$\begin{array}{c}\text { Skor } \\
\text { Indeks } \\
\text { Tertinggi }\end{array}$} & \multirow[b]{2}{*}{ Mean } \\
\hline & & SS & $S$ & TS & STS & & \\
\hline Komitmen & & 51 & 66 & 3 & & & \\
\hline Organisasi & X1.1 & $42,50 \%$ & $55 \%$ & $2,50 \%$ & & 408 & 3,400 \\
\hline Tingkat & & 41 & 70 & 9 & & & \\
\hline $\begin{array}{l}\text { Keseriusan } \\
\text { Kecurangan }\end{array}$ & X2.7 & $34,20 \%$ & $58,30 \%$ & $7,50 \%$ & & 392 & 3,266 \\
\hline Personal Cost & X3.7 & $\begin{array}{c}49 \\
40,80 \%\end{array}$ & $\begin{array}{c}59 \\
49,20 \%\end{array}$ & $\begin{array}{c}11 \\
9,20 \%\end{array}$ & $\begin{array}{c}1 \\
0,80 \%\end{array}$ & 396 & 3,300 \\
\hline Niat & & 17 & 97 & 5 & 1 & & \\
\hline $\begin{array}{l}\text { Whistleblowing } \\
\text { Fraud }\end{array}$ & Y.2 & $14,20 \%$ & $80,80 \%$ & $4,20 \%$ & $0,80 \%$ & 370 & 3,083 \\
\hline
\end{tabular}

Sumber: Data Penelitian, 2021

Analisis statistik deskriptif untuk variabel komitmen organisasi memiliki nilai indeks tertinggi yang mengindikasikan bahwa pegawai memiliki persepsi mengenai komitmen organisasi berada pada item pernyataan pertama dimana pegawai merasa memiliki keluarga baru di dalam organisasi tersebut, dengan skor 408 dan mean sebesar 3,400. Variabel tingkat keseriusan kecurangan memiliki nilai indeks tertinggi yang berada pada item pernyataan tujuh dimana pegawai akan melaporkan tindakan kecurangan yang dilakukan oleh rekan kerjanya apabila jumlahnya material, dengan skor 392 dan mean sebesar 3,266. Variabel personal cost memiliki nilai indeks tertinggi pada item pernyataan tujuh dimana menyatakan bahwa karyawan akan memiliki peluang yang lebih besar untuk mendapatkan ancaman apabila ia tidak menyembunyikan identitassnya, dengan skor 396 dan mean sebesar 3,300. Sedangkan variabel niat whistleblowing fraud memiliki nilai 
indeks tertinggi yang berada pada item pernyataan dua dimana pegawai berencana untuk melakukan tindakan pelaporan penyimpangan kepada atasannya untuk mengungkap penyimpangan yang terjadi dalam organisasi apabila ia mengetahuinya, dengan skor 370 dan mean sebesar 3,083.

Tabel 2. Hasil Uji Validitas

\begin{tabular}{|c|c|c|c|c|c|c|c|c|}
\hline \multirow{2}{*}{ Variabel } & \multicolumn{7}{|c|}{ Item Pernyataan } & \multirow{2}{*}{ Ket. } \\
\hline & 1 & 2 & 3 & 4 & 5 & 6 & 7 & \\
\hline \multicolumn{9}{|c|}{$\begin{array}{l}\text { Komitmen Organisasi } \\
\text { (X1) }\end{array}$} \\
\hline Person Coreelation & 0,577 & 0,604 & 0,402 & 0,515 & 0,654 & 0,561 & 0,605 & \multirow{2}{*}{ Valid } \\
\hline Sig (2-Tailed) & 0,000 & 0,000 & 0,000 & 0,000 & 0,000 & 0,000 & 0,000 & \\
\hline \multicolumn{9}{|c|}{ Tingkat Keseriusan } \\
\hline Kecurangan $(X 2)$ & & & & & & & & \multirow{3}{*}{ Valid } \\
\hline Person Coreelation & 0,553 & 0,608 & 0,596 & 0,389 & 0,619 & 0,473 & 0,594 & \\
\hline Sig (2-Tailed) & 0,000 & 0,000 & 0,000 & 0,000 & 0,000 & 0,000 & 0,000 & \\
\hline \multicolumn{9}{|l|}{ Personal Cost $(\mathrm{X} 3)$} \\
\hline Person Coreelation & 0,550 & 0,691 & 0,711 & 0,697 & 0,476 & 0,628 & 0,553 & \multirow[t]{2}{*}{ Valid } \\
\hline Sig (2-Tailed) & 0,000 & 0,000 & 0,000 & 0,000 & 0,000 & 0,000 & 0,000 & \\
\hline \multicolumn{9}{|c|}{ Niat Whistleblowing } \\
\hline Fraud $(\mathrm{Y})$ & & & & & & & & \multirow{3}{*}{ Valid } \\
\hline Person Coreelation & 0,677 & 0,733 & 0,717 & 0,628 & 0,650 & 0,655 & 0,397 & \\
\hline Sig (2-Tailed) & 0,000 & 0,000 & 0,000 & 0,000 & 0,000 & 0,000 & 0,000 & \\
\hline
\end{tabular}

Sumber: Data Penelitian, 2021

Hasil uji validitas menunjukkan bahwa variabel dependen dan independen beserta item-item pernyataan yang diuji menggunakan aplikasi SPSS V.22 dinyatakan valid. Hal tersebut dikarenakan nilai Corrected Item-Corelation lebih kecil dari signifikan 0,05.

Tabel 3. Hasil Reliabilitas

\begin{tabular}{lcc}
\hline \multicolumn{1}{c}{ Variabel } & Cronbach's Alpha & Keterangan \\
\hline Komitmen Organisasi (X1) & 0,635 & Reliabel \\
Tingkat Keseriusan Kecurangan $(\mathrm{X} 2)$ & 0,609 & Reliabel \\
Personal Cost $(\mathrm{X} 3)$ & 0,727 & Reliabel \\
Niat Whistleblowing Fraud $(\mathrm{Y})$ & 0,761 & Reliabel \\
\hline
\end{tabular}

Sumber: Data Penelitian, 2021

Seluruh variabel memiliki nilai cronbach's alpha yang lebih besar dari 0,6. Maka dari itu dapat ditarik kesimpulan jika instrumen yang digunakan di dalam kuesioner untuk menjelaskan variabel Komitmen Organisasi, Tingkat Keseriusan Kecurangan, Personal Cost, dan Niat Whistleblowing Fraud dapat dinyatakan reliabel. Hal tersebut mengindikasikan tiap-tiap item pernyataan yang digunakan mampu memperoleh suatu data yang konsisten, apabila pernyataan tersebut diajukan kembali maka dapat memperoleh jawaban yang relatif sama dengan jawaban yang sebelumnya. 
Tabel 4. Hasil Uji Hipotesis

\begin{tabular}{|c|c|c|c|c|c|c|}
\hline \multirow[t]{2}{*}{ Model } & \multicolumn{2}{|c|}{$\begin{array}{l}\text { Unstandardized } \\
\text { Coefficients }\end{array}$} & \multirow[t]{2}{*}{ R Square } & \multirow{2}{*}{$\begin{array}{l}\text { Adjusted R } \\
\text { Square }\end{array}$} & \multirow[t]{2}{*}{$\mathrm{T}$} & \multirow[t]{2}{*}{ Sig. } \\
\hline & $\mathrm{B}$ & Std. Error & & & & \\
\hline 1 (Constant) & 10,476 & 3,078 & 0,168 & 0,146 & 3,403 & 0,001 \\
\hline $\begin{array}{l}\text { Komitmen } \\
\text { Organisasi }\end{array}$ & 0,185 & 0,097 & & & 1,912 & 0,058 \\
\hline $\begin{array}{l}\text { Tingkat Keseriusan } \\
\text { Kecurangan }\end{array}$ & 0,362 & 0,100 & & & 3,626 & 0,000 \\
\hline Personal Cost & 0,076 & 0,089 & & & 0,860 & 0,392 \\
\hline
\end{tabular}

Sumber: Data Penelitian, 2021

Penghitungan seberapa besar pengaruh antara variabel independen yakni Komitmen Organisasi, Tingkat Keseriusan Kecurangan, dan Personal Cost terhadap variabel dependen yakni Niat Whistleblowing Fraud, dapat dilakukan dengan uji regresi linear berganda. Hasil uji tersebut akan menunjukkan nilai dari konstanta dan juga koefisien regresi linear berganda dari masing-masing variabel independen. Adapun model dari regresi linear berganda yang didapatkan dari hasil pengujian adalah sebagai berikut.

$$
\mathrm{Y}=10,476+0,185 \mathrm{X}_{1}+0,362 \mathrm{X}_{2}+0,076 \mathrm{X}_{3}+\varepsilon
$$

Nilai konstanta sebesar 10,476 menunjukkan bahwa apabila variabel independen yakni Komitmen Organisasi, Tingkat Keseriusan Kecurangan, dan Personal Cost adalah nol, maka Niat Whistleblowing Fraud bakal terjadi sebesar 10,476. Koefisien regresi dari variabel Komitmen Organisasi $\left(X_{1}\right)$ sebesar 0,185 menunjukkan jika setiap ada perubahan kenaikan satu satuan variabel Komitmen organisasi, maka dapat meningkatkan Niat Whistleblowing Fraud sebesar 0,185.Koefisien regresi dari variabel Tingkat Keseriusan Kecurangan $\left(\mathrm{X}_{2}\right)$ sebesar 0,362 menunjukkan jika setiap ada perubahan kenaikan satu satuan variabel Tingkat Keseriusan Kecurangan, maka dapat meningkatkan Niat Whistleblowing Fraud sebesar 0,362. Koefisien regresi dari variabel Personal Cost $\left(\mathrm{X}_{3}\right)$ sebesar 0,076 menunjukkan jika setiap ada perubahan kenaikan satu satuan variabel Personal Cost, maka dapat meningkatkan Niat Whistleblowing Fraud sebesar 0,076.

Apabila regresi yang digunakan memiliki lebih dari dua variabel independen maka digunakan nilai AdjustedR ${ }^{2}$ sebagai koefisien determinasi (Santoso, 2013). Nilai Adjustes R Square dari hasil pengujian koefisien determinasi sebesar 0,146 yang artinya bahwa niat whistleblowing fraud aparatur daerah Kota Palopo sebesar 14,6\% dipengaruhi oleh Komitmen Organisasi, Tingkat Keseriusan Kecurangan, dan Personal Cost. Sisanya sebesar 85,4\% dipengaruhi variabel lain yang belum diteliti pada penelitian ini.

Uji-t (parsial) digunakan untuk meneliti apakah Komitmen Organisasi, Tingkat Keseriusan Kecurangan, dan Personal Cost berpengaruh terhadap Niat Whistleblowing Fraud dari aparatur daerah Kota Palopo. Hipotesis satu $\left(\mathrm{H}_{1}\right)$ yang diajukan adalah Komitmen Organisasi berpengaruh terhadap Niat Whistleblowing Fraud Aparatur Daerah Kota Palopo. Hasil analisis menunjukkan variabel Komitmen Organisasi memiliki tingkat signifikan sebesar 0,058 > 0,05 Sehingga dapat disimpulkan bahwa $\mathrm{H}_{1}$ ditolak. Hal ini mengisyaratkan bahwa Komitmen Organisasi tidak berpengaruh terhadap Niat Whistleblowinng Fraud aparatur daerah Kota Palopo. 
Komitmen Organisasi yang dijelaskan dalam teori perilaku terencana sebagai bagian dari subjective norms atau norma subjektif, rasa komitmen organisasi yang tinggi yang dimiliki oleh diri pegawai dapat menumbuhkan rasa ingin meningkatkan kesejahteraan serta keberhasilan organisasinya. Sehingga apabila pegawai melihat bahwa terdapat tindakan kecurangan yang bisa saja mengganggu keberhasilan dari tujuan organisasinya maka akan timbul niat dalam dirinya untuk mengambil tindakan melaporkan kasus kecurangan tersebut. Dalam penelitian ini hal tersebut belum mampu dibuktikan dan dijelaskan dengan baik.

Ada tidaknya maupun rendah atau tingginya komitmen organisasi yang dimiliki aparatur daerah Kota Palopo, kurang mempengaruhi niat mereka untuk melakukan whistleblowing. Hal ini dapat dilihat kembali dari sisi Theory of Reassoned Action (TRA) oleh Ajzen \& Fishbein (1980). Teori ini disusun berdasarkan asumsi bahwa keinginan individu itu sendiri untuk melakukan ataupun tidak melakukan suatu perilaku dengan mempertimbangkan informasi dapat mempengaruhi perilakunya. Perilaku dikendalikan secara penuh oleh individu. Niat individu ditentukan oleh sebuah dasar penentu yang berkaitan dengan faktor yang berasal dari pribadi sendiri serta berasal dari lingkungan sosial.

Pada penelitian ini, tidak berpengaruhnya komitmen organisasi terhadap niat untuk melakukan whistleblowing fraud juga bisa berasal dari kurangnya rasa percaya dari pegawai bahwa laporan mereka mengenai tindakan kecurangan yang terjadi, akan segera ditindak lanjuti oleh pihak organisasi. Hasil ini juga selaras dengan hasil penelitian Sartika \& Mulyani (2020), Dewi \& Indraswarawati (2020), Lestari \& Yaya (2017) bahwa Komitmen Organisasi tidak berpengaruh terhadap Niat untuk melakukan Whistleblowing Fraud. Akan tetapi penelitian dari Dewi \& Dewi (2019) menunjukkan hasil yang berbeda, bahwa Komitmen Organisasi berpengaruh signifikan terhadap intensi atau niat dalam melakukan Whistleblowing. Dimana komitmen organisasi yang dimiliki semakin tinggi maka juga dapat semakin meningkatkan intensi untuk melakukan suatu tindakan whistleblowing.

Hipotesis dua $\left(\mathrm{H}_{2}\right)$ yang diajukan adalah Tingkat Keseriusan Kecurangan berpengaruh terhadap Niat Whistleblowing Fraud Aparatur Daerah Kota Palopo. Hasil analisis yang menunjukkan variabel Tingkat Keseriusan Kecurangan memiliki nilai signifikan 0,000 $<0,05$. Sehingga hal tersebut bisa disimpulkan bahwa $\mathrm{H}_{2}$ diterima. Tingkat keseriusan kecurangan dalam teori perilaku terencana berhubungan dengan attitude toward behavior, yakni tindakan yang diambil dapat memberikan hal positif dan bermanfaat bagi organisasi. Hal tersebut dapat dibuktikan dengan baik. Dimana, pegawai yang melihat dampak serius dari kecurangan yang bisa mengakibatkan kerugian bagi organisasinya akan menimbulkan niat dalam diri mereka untuk mengambil tindakan pelaporan terhadap kecurangan yang terjadi. Sehingga kecurangan tersebut bisa diatasi dan tidak lagi merugikan organisasi.

Hasil penelitian ini sejalan dengan penelitian yang dilakukan olehPrimasari dan Fidiana (2020), Aida et al . (2019), Busra et al. (2019) bahwa Tingkat Keseriusan Kecurangan berpengaruh terhadap niat melakukan whistleblowing. Semakin serius suatu kecurangan yang terjadi, maka akan semakin kuat niat yang timbul untuk 
melakukan tindakan whistleblowing. Apabila materialitas kecurangan memiliki tingkatan yang tinggi maka dapat menaikkan besaran dampak kerugian dan juga bahaya, hal tersebut menunjukkan semakin tidak etisnya suatu tindakan kecurangan. Akan tetapi hasil yang berbeda ditunjukkan dalam penelitian yang dilakukan oleh Sartika dan Mulyani (2020), bahwa tingkat keseriusan kecurangan tidak berpengaruh terhadap niat melakukan whistleblowing.

Hipotesis tiga $\left(\mathrm{H}_{3}\right)$ yang diajukan adalah Personal Cost berpengaruh terhadap Niat Whistleblowing Fraud aparatur daerah Kota Palopo. Hasil analisis menunjukkan variabel Personal Cost memiliki signifikansi sebesar 0,392 >0,05. Hal ini bisa disimpulkan jika $\mathrm{H}_{3}$ ditolak yang mengisyaratkan bahwa Personal Cost tidak berpengaruh terhadap Niat Whistleblowing Fraud aparatur daerah Kota Palopo. Personal cost dalam teori perilaku terencana, dijelaskan sebagai perceived behavior control atau persepsi kontrol perilaku. Pegawai akan mempertimbangkan kemungkinan terburuk atau risiko yang nantinya bisa saja mereka terima akibat dari tindakan pelaporan yang mereka lakukan. Dalam penelitian ini hal tersebut tidak dapat dibuktikan dengan baik. Dikarenakan aparatur daerah Kota Palopo telah siap dengan segala risiko yang mungkin timbul akibat dari melakukan tindakan whistleblowing. Mereka dapat mengelola ataupun menghindari risiko pembalasan dari pihak-pihak yang terlibat dalam kasus kecurangan tersebut maupun dari sesama anggota organisasi. Mereka juga telah familiar terhadap hal yang berkaitan kecurangan itu sendiri, sehingga Personal Cost tidak lagi mempengaruhi niat mereka untuk melakukan tindakan wistleblowing fraud.

Hasil penelitian ini didukung dari sisi Social Cognitive Theory (SCT) yang dikembangkan oleh Bandura (1989). Pervin \& Jhon (2001) mengemukakan bahwa teori sosial kognitif ini menekankan pada manusia sebagai individu aktif dan menggunakan potensi kognitif yang dimilikinya untuk memberikan gambaran pada suatu kejadian, mengantisipasi sesuatu hal, dan juga memilih serangkaian tindakan yang mesti dilakukan. Manusia bukan makluk pasif yang hanya menerima dorongan naluri maupun pengaruh dari lingkungan luar.

Hasil penelitian ini dimana personal cost tidak berpengaruh terhadap niat melakukan tindakan Whistleblowing, sejalan dengan hasil penelitian yang dilakukan Aida et al. (2019). Pemerintah Daerah Kota Palopo telah memiliki Peraturan Walikota No. 30 Tahun 2020 mengenai whistleblowing system. PERWALI tersebut sebagai acuan dalam menangani pengaduan tindak kecurangan, acuan bagi masyarakat atau pegawai yang mengetahui ataupun informasi dan buktibukti mengenai tindak kecurangan, serta menjadi acuan dalam memberikan perlindungan bagi pelapor (whistleblower). Sehingga aparatur daerah tidak lagi menjadikan personal cost sebagai pertimbangan mereka dalam mengambil keputusan apakah akan melakukan tindakan whistleblowing atau tidak. Akan tetapi penelitian dari Lestari \&c Yaya (2017) menunjukkan hasil yang berbeda yakni personal cost memiliki pengaruh negatif terhadap niat melakukan tindakan whistleblowing. Personal cost dipandang sebagai suatu prediktor yang dapat menurunkan niat dalam melakukan tindakan whistleblowing. 


\section{SIMPULAN}

Komitmen Organisasi tidak berpengaruh terhadap Niat Whistleblowing Fraud aparatur daerah Kota Palopo. Hal tersebut dikarenakan ada tidak maupun tinggi atau rendah komitmen organisasi yang dimiliki oleh aparatur da erah KotaPalopo, kurang mempengaruhi niat mereka untuk melakukan tindakan whistleblowing.Tingkat Keseriusan Kecurangan berpengaruh terhadap Niat Whistleblowing Fraud aparatur daerah Kota Palopo. Semakin serius suatu kecurangan yang terjadi, maka akan semakin kuat niat yang timbul pada diri pegawai untuk melakukan tindakan whistleblowing.Personal Cost tidak berpengaruh terhadap Niat Whistleblowing Fraud aparatur daerah Kota Palopo. Hal ini karena mereka telah siap dengan segala risiko yang mungkin timbul akibat dari melakukan tindakan whistleblowing. Mereka dapat mengelola ataupun menghindari risiko tersebut. Selain itu telah terdapat PERWALI Kota Palopo No. 30 Tahun 2020 mengenai whistleblowing system.

Responden yang menjadi sampel hanya berfokus pada aparatur daerah yang bekerja pada dua organisasi perangkat daerah saja, yakni Dinas PUPR dan BPKAD dan belum mencakup semua organisasi perangkat daerah yang ada di Kota Palopo. Variabel yang diteliti hanya Komitmen Organisasi, Tingkat Keseriusan Kecurangan, dan Personal Cost saja dan menghasilkan pengaruh yang kecil terhadap niat aparatur daerah Kota Palopo untuk melakukan whistleblowing fraud. Agar penelitian selanjutnya bisa lebih baik lagi maka diharapkan peneliti dapat memperluas cakupan responden sehingga hasil penelitian dapat digeneralisasi secara umum. Menggunakan teknik pengumpulan berupa pengamatan, observasi, atau wawancara secara langsung kepada responden agar data yang diperoleh lebih jelas serta akurat. Mengembangkan variabel-variabel lain yang sekiranya dapat lebih mempengaruhi niat dari aparatur daerah dalam melakukan whistleblowing fraud, seperti: sikap, tanggung jawab pribadi, dan persepsi dukungan organisasi.

\section{REFERENSI}

Aida, R., Helmy, H., \& Setiawan, M. A. (2019). Faktor-faktor yang Mempengaruhi Minat Pegawai Negeri Sipil Untuk Melakukan Tindakan Whistleblowing. Jurnal Eksplorasi Akuntansi, 1(4), 1633-1649.

Ajzen, I. (1991). The Theory of Planned Behavior Organizational Behavior and Human Decision Processes. Organizational Behavior and Human Decision Processes, 50(2), 179-211.

Ajzen, I. Fishbein. M. (1980). Understanding attitudes and predicting behavior. Englewood cliffs, NJ. Prntice Hall.

Albrecht, ., \& dkk. (2014). Akuntansi Forensik. Salemba Empat.

Alwi, H., \& Helmayunita, N. (2020). Pengaruh Sikap, Personal Cost Of Reporting , dan Tingkat Keseriusan Kecurangan Terhadap Intention Whistleblowing pada Pemerintah Daerah. Jurnal Eksplorasi Akuntansi, 2(1), 2445-2465.

Association of Certified Fraud Examiners (ACFE) Indonesia Chapter. (2019). Survei Fraud Indonesia 2019. In Acfe Indonesia.

Brennan, N., \& Kelly, J. (2007). A Study of Whistleblowing among Trainee Auditors. British Accounting Review, 39(1), 61-87.

Busra, N. F., Ahyaruddin, M., \& Agustiawan. (2019). Pengaruh Tingkat Keseriusan 
Kecurangan , Personal Cost, dan Komitmen Organisasi terhadap Kecenderungan Melakukan Whistleblowing. Muhammadiyah Riau Accounting and Business Journal, 1(1).

Dewi, D. A. R. A., \& Indraswarawati, S. A. P. A. (2020). Pengaruh Personal Cost, Komitmen Organisasi, Sensitivitas Etika dan Machiavellian Terhadap Minat Melakukan Whistleblowing pada Organisasi Perangkat Daerah Kabupaten Gianyar. Hita Akuntansi dan Keuangan, 1(2), 325-357.

Dewi, N. K. A. R., \& Dewi, I. G. A. A. P. (2019). Pengaruh Profesionalisme, Komitmen Organisasi, dan Sensitivitas Etika Terhadap Intensi Dalam Melakukan Whistleblowing: Studi Kasus Pada Badan Pengelola Keuangan dan Aset Daerah (BPKAD) Provinsi Bali. Jurnal Ilmiah Akuntansi \& Bisnis, 4(1), $1-13$.

Indonesian Corruption Watch. (2020). Laporan Pemantauan Tren Penindakan Kasus Korupsi Semester I 2020.

Lestari, R., \& Yaya, R. (2017). Whistleblowing dan Faktor-Faktor yang Memengaruhi Niat Melaksanakannya oleh Aparatur Sipil Negara. Jurnal Akuntansi, XXI(3), 336-350.

Marliza, R. (2018). Pengaruh Personal Cost Of Reporting, Komitmen Organisasi, dan Tingkat Keseriusan Kecurangan Terhadap Niat Melakukan Whistleblowing (Studi Empiris pada Organisasi Perangkat Daerah Kota Payakumbuh). Jurnal Akuntansi, 6(1), 1-20.

Mediaty, M., Pontoh, G. T., Darmawati, D., Usman, H., \& Mustafa, S. (2020). Whistleblowing As an Effort to Reduce Fraud Actions. International Journal of Innovative Science and Research Technology, 5(12), 393-400.

Padmasari, S. I. (2019). 2 Pejabat Pernkot Palopo Jadi Tersangka Kasus Korupsi Proyek Air Minum. Merdeka.com. https:/ /www.merdeka.com/peristiwa/2-pejabatpemkot-palopo-jadi-tersangka-kasus-korupsi-proyek-air-minum.html

Peraturan Walikota Palopo No. 30 Tahun 2020 Tentang Pedoman Penanganan Pelaporan Pengaduan (Whistleblowing System) Dugaan Tindak Pidana Korupsi.

Primasari, R. A., \& Fidiana, F. (2020). Whistleblowing Berdasarkan Intensitas Moral, Komitmen Profesional, dan Tingkat Keseriusan Kecurangan. Jurnal Kajian Akuntansi, 4(1), 63-77.

Sartika, D., \& Mulyani, F. (2020). Pengaruh Sifat Machiavellian, Lingkungan Etika, Komitmen Organisasi, dan Tingkat Keseriusan Kecurangan Terhadap Niat Melakukan Whistleblowing (Studi Empiris pada BPKAD di Kota Padang). Menara Ilmu, XIV(1), 24-39.

Septianti, Windy. (2013). "Pengaruh Faktor Organisasional, Individual, Situasional, dan Demografis Terhadap Niat Melakukan Whistleblowing Internal". Manado: Simposium Nasional Akuntansi.

Setyawati, I., Ardiyani, K., \& Sutrisno, C. R. (2015). Faktor-Faktor Yang Mempengaruhi Niat untuk Melakukan Whistleblowing Internal (The Factors Influencing Internal Whistleblowing Intentions). Jurnal Ekonomi dan Bisnis, 17(2), 22-33.

Winardi, R. D. (2013). the Influence of Individual and Situational Factors on Lower-Level Civil Servants Whistle-Blowing Intention In Indonesia. Economy and Business, 28(3), 361-376. 